of health visitors, and feedback will be sent yearly to primary care teams. The current citywide rates of breast feeding at birth and at 3 months are $50 \%$ and $25 \%$ respectively; rates for small areas are available and can be used to evaluate local initiatives.

Secondly, maternity units should strongly encourage staff to promote breast feeding. ${ }^{7}$ This should include regular training and updating; monitoring such practices as separating mothers from babies after birth and offering water or cows' milk to babies; and assigning responsibility for breast feeding to a senior member of staff. This person could also fill the role of lactation consultant, to provide help in problem cases. ${ }^{8}$ A close eye should be kept on the provision of samples and the promotion of milk formula on the wards.

Thirdly, the hospital unit or trust should seek the status of a "baby friendly hospital." This Unicef initiative recognises the part that hospitals have to play in encouraging breast feeding and rewards hospitals that are doing well. To receive the award, a hospital must have a 10 point policy that covers all the practices mentioned above. This initiative allows public pressure to be brought to bear on hospitals that are not up to the mark.

Finally, maternity units should encourage better cooperation with voluntary groups such as the National Childbirth Trust and La Leche League. These groups can do much to provide the individual support that breast feeding mothers may fail to receive from hard pressed NHS staff. In the community the La Leche League's new peer counselling scheme is an exciting way to improve support in disadvantaged communities by offering training to breast feeding mothers, who then act as a local focus of skill.

Now that the health benefits of breast feeding are so well documented purchasers should insist that hospital practices encourage rather than discourage mothers from practising it.

TONY WATERSTON

Unityne Health,

Newcastle Upon Tyne NE4 8NZ

Consultant community paediatrician

Royal Victoria Infirmary,

JEAN DAVIES

Newcastle Upon Tyne NE1 4LP

Community midwife

1 Winikoff B. Modification of hospital practices to remove obstacles to successful breastfeeding. In Jelliffe DB, Jelliffe EFP, eds. Programmes to promote breastfeeding. Oxford: Oxford Universit Press, 1988:279-86.

2 White A, Freeth S, O'Brien M. Infant feeding 1990. London: HMSO, 1992.

3 Beeken S, Waterston T. Health service support of breasffeeding - are we practising what we preach? BMF 1992;305:285-7.

4 Lewinski C. Nurses' knowledge of breastfeeding in a clinical setting. Fournal of Human Lactation 1992;8:143-8.

5 Bergevin Y, Dougherty C, Kramer M. Do infant formula samples shorten the duration of breast feeding. Lancet 1983;i:1148-51.

feeding. Lancet 1983;i:1148-51.

7 Renfrew M, Fisher C, Arms S. Best feeding: getting breastfeeding right for you. Berkeley, CA: Celestial Arts, 1990.

8 Jelliffe DB, Jelliffe EFP, Latharn M, Greiner T. Devising breastfeeding programmes: some practical realities and recent developments. In: Jelliffe DB, Jelliffe EFP, eds. Programmes to promote breastfeeding. Oxford: Oxford University Press, 1988:426-44.

9 Grant J. State of the world's children 1993. Oxford: Oxford University Press, 1993.

\title{
Medical accidents: no such thing?
}

\section{More precise terminology would help doctors to reduce harm}

The use of the word "accident" in the title of the excellent new book Medical Accidents ${ }^{1}$ stands in stark contrast to its abandonment in other disciplines, such as the study of traffic safety. ${ }^{2}$ Fifteen years ago Doege argued in an editorial in the New England Fournal of Medicine that it was time "for medicine to dispose of the idea of 'accident' and 'accidental injury'." Others have also reasoned persuasively that the conceptual ambiguities encompassed in the word accident disqualify it from technical use, notwithstanding its near universal general use. ${ }^{4}$ Yet its use in medical settings continues to mislead.

"Accident" conveys a sense that the losses incurred are due to fate and are therefore devoid of rational explanation or predictability. Yet the motivation to study subjects like traffic safety is to discover factors that influence the likelihood of occurrence of, and resulting harm from, "crashes," the preferred term. There are very few traffic related deaths for which the word crash is inappropriate (the minuscule fraction of deaths from drowning and fires not initiated by crashes). Some crashes are purposeful acts, including suicide ${ }^{56}$ and homicide, for which the word accident would be inappropriate even in popular use.

The word crash indicates in a simple factual way what is observed, while accident seems to suggest in addition a general explanation of why it occurred without any evidence to support such an explanation. The word cause is also avoided ${ }^{2}$ because it conveys the notion of a single cause in the deterministic sense in which the term is used in the physical sciences or engineering.

Suppose on a dark rainy morning a young man argues with his wife about the purchase of a sofa, leaves the house late for work in a rage, drives his poorly maintained car too fast on a badly designed and poorly lit curve, skids, and is killed in a crash with a truck driven by an older driver. It is of little value to say that the death was "caused" by the car driver's youth or maleness, the truck driver's old age, the car's bald tyres, the high cost of sofas, emotional stress, the non-use of a safety belt, inadequate enforcement of speed limits by the police, rain, or any other of the many factors which, if different on this particular occasion, would have prevented the death. What is important is to know what factors affect risk, and by how much, and to use such knowledge to reduce future risks.

In air transport the word crash has achieved general public acceptance, especially as airport security procedures remind air travellers that crashes may indeed not fit the popular notion of accident. In many regards, air crashes differ fundamentally from car crashes and may be more analogous to the medical case. In the medical and air transport cases the main decision makers are highly trained professionals, and rarely is there any egregious violation of elementary safety procedures, as commonly occurs when car drivers are drunk, violate speed limits, or jump red lights. Unfortunately, it is too easy a step from identifying factors associated with losses in transport or medicine to adopting a narrow focus on assigning blame. Perhaps this is what gives "accident" its most potent appeal-the sense that it exonerates participants from responsibility.

Adverse outcomes of medical procedures have an even wider range of potential explanatory variables than apply to the transportation crashes described above. A patient may die even though every aspect of the procedure was performed flawlessly in the light of present knowledge; death during a lengthy procedure may even be unrelated to the procedure or 
the condition it addressed. In such cases detailed investigation would lead to no recommendations for change. At the other end of this wide spectrum is the possibility of professional malfeasance (see the paper by Graham Neale on $p 1483^{7}$ ), and even purposeful harmful acts are not impossible. Unlike the airline pilot, medical professionals do not share the fate of those in their care. Even if the patient dies because the hospital burns down in the middle of the operation this should still not be called an accident because buildings catch fire for reasons.

As the issues in the medical case are more complex than in the transport case the reasons for replacing the word accident by a more objective and crisp word are all the more compelling. While some might argue that this is a pedantic quibble to be dismissed by "What's in a name?", I think that the benefits of more precise terminology would be substantial. The central issue is that "accident" conveys a sense that bad outcomes are to be explained in terms of fate and luck rather than a set of understandable, and possibly changeable, antecedents. The opportunities to reduce harm will increase if we keep uppermost in our thinking that "The fault. . . is not in our stars, but in ourselves."

LEONARD EVANS Principal research scientist

Research and Development Center,

Automotive Safety and Health Research Department,

General Motors Corporation

Warren, MI 48090-9055,

USA

1 Vincent O, Ennis M, Audley R, eds. Medical accidents. Oxford: Oxford University Press, 1993.

2 Evans L. Traffic safety and the driver. New York: Van Nostrand Reinhold, 1991.

3 Doege TC. Sounding board-an injury is no accident. N Engl f Med 1978;298:509-10.

Langley JD. The need to discontinue the use of the term "accident" when referring to unintentional injury events. Accid Anal Prev 1988;20:1-8.

5 Bollen KA, Philipps DP. 1981 suicidal motor vehicle fatalities in Detroit: a replication. America fournal of Sociology 1981:87:404-2.

Philipps DP. Suicide, motor vehicle fatalities, and the mass media: evidence towards a theory of suggestion. American foumal of Sociology 1979;84:1150-74

7 Neale G. A clinical analysis of 100 medico-legal cases. BMf 1993;307:1483-7.

\section{Explaining referral variation}

\section{GPs cannot afford to be uninterested in the topic}

Yet again, two papers on hospital referrals in this week's

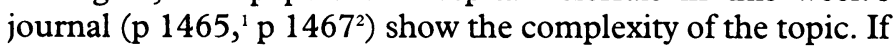
their findings are indicative of the rest of Britain, then general practices' referral rates would seem to vary by a factor of four. Despite new work on this topic ${ }^{34}$ questions remain on what this variation means and how to influence it.

Much anecdotal support exists concerning the issue of "inappropriate" referrals to hospital. Fertig and colleagues have used the implicit criteria of hospital specialists to judge whether referrals received by them were inappropriate. ${ }^{1}$ Except in orthopaedic cases, about $15 \%$ were judged to be so, with referrals between hospital specialists faring no differently than those from general practice. The authors calculate that reducing "inappropriate" referrals to zero would result in marginal overall reduction in referral rates. Moreover, using a set of local external clinical guidelines, Fertig and colleagues found evidence of underreferral. So the net result of ensuring that all referrals were appropriate would be to improve the effectiveness of the process rather than reduce numbers.

Importantly though, none of this work incorporates the views of patients; they may not share the definitions of general practitioners or hospital specialists. Like it or not, a person's right to hospital referral is enshrined in the general practice contract, an issue that is rarely debated in discussions on the gatekeeper role of the general practitioner.

Turning to ways of influencing doctors' behaviour, de Marco and colleagues sought general practitioners' views on which factors influenced their referral behaviour. ${ }^{2}$ East Anglian doctors nominated four important factors: ease of access, interests and skills of the doctors, patient pressure or demand, and fear of litigation. Only obliquely do doctors seem to identify their personal traits as relevant.

Other studies have identified that a relative inability to tolerate uncertainty or a reduction in that tolerance in response to an unexpected event affects referral decision making. ${ }^{5}$ Yet how often is the management of uncertainty discussed in undergraduate or vocational training curriculums? Perhaps it is not surprising, therefore, that the authors found it difficult to engage doctors in a discussion of their referral practice and the doctors from units with high rates were defensive. In the uncertain world of primary care it may be difficult for doctors to acknowledge their anxieties about decision making. It may well be in their patients' best interests for doctors to use the "when in doubt, refer" motto.

While studies have found that feedback on other aspects of clinical practice influences the process of care ${ }^{6}$ feedback on referral seems more problematic. In de Marco's study the feedback was treated with disdain, and a similar response greeted a feedback package in the north of England. ${ }^{7}$ But this position is unsustainable. Despite the complexities surrounding referral and legitimate concerns about the quality of the techniques of providing feedback, general practitioners have to accept that information on referrals has a part to play in the effective use of resources. For every case referred without benefit to the patient's health there is an opportunity cost for others.

Does fundholding or health commissioning hold the answer? Both studies published in this week's journal were undertaken before fundholding became commonplace. Devolving responsibility for ensuring value for money to fundholders or to non-fundholding locality groups in association with commissioning agencies may be the missing element in the equation. But there is a need to recognise that the behaviour of individual doctors, and the factors underlying this, are key elements in the referral conundrum. Undergraduate and postgraduate education must pay more attention to this important aspect of medical decision making.

ALLEN HUTCHINSON Professor and head of department

Department of Public Health Medicine,

University of Hull,

Hull HU6 7RX

1 De Marco P, Cain C, Lockwood T, Roland M. How valuable is feedback of information on hospital referral patterns? Lessons from visits to 92 East Anglian practices. $B M \mathcal{F} 1993 ; 307: 1465-6$.

2 Fertig A, Roland M, King H, Moore T. Understanding variation in general practitioner referral rates: are inappropriate referrals important and would guidelines help to reduce rates of referral? BMf 1993;307:1467-70.

3 Roland M, Coulter A, eds. Hospital referrals. Oxford: Oxford University Press, 1993.

4 Noone A, Goldacre M, Coulter A, Seagroatt V. Do referral rates vary widely between practices and does supply of services affect demand? $₹ R$ Coll Gen Pract 1989;39:404-7.

Newton J, Hayes V, Hutchinson A. Factors influencing general practitioner referral decisions. Family Practitioner 1991;8:308-13.

6 Mugford M, Banfield P, O'Hanlon M. Effects of feedback of information on clinical practice: review $B M 71991 ; 303: 398-402$.

McColl E, Newton J, Hutchinson A. An agenda for change in referral: consensus for general practice. $B r f$ Gen Pract (in press). 